Notes and miscellanea

\section{Actual hazard of methyl bromide fumigation in soil disinfection}

of detecting or measuring ambient methyl bromide levels.

\section{British Pest Control Association, Alembic House, 93 Albert Embankment, London SE1 7TU.}

The authors of this paper (May 1982) are to be esteemed for their concern about operator's safety. Apart from a few understandable errors, careful study of their paper shows that a great number of operating instructions or precautions suggested in the Health and Safety Executive's guidance note $\mathrm{GSl}^{1}$ were infringed by the three operating teams and that most of their conclusions are already de rigeur in the United Kingdom (as they are also in the Belgian Labour Ministry's "Labour Protection and Labour Relations"). Furthermore, one at least of their observations is questionable.

On page 143 the authors write that ". . . there is a partial absorption of methyl bromide through the skin, especially when humid." Arguments for the absorption of methyl bromide through the skin were disproved by cases in 1940 and 1945 , in which very severe skin damage to army tank crews using methyl bromide fire extinguishers was not accompanied by any of the symptoms of methyl bromide poisoning. $^{2-4}$ The subsequent general acceptance that methyl bromide is not absorbed through the skin ${ }^{5}$ was reinforced by the clear distinction between severe skin damage caused by prolonged skin exposure and the milder sequelae to the central nervous system after inhalation.

The statement that "The use and application of methyl bromide as a fumigant will be completely abandoned and replaced by less toxic disinfection methods if future studies should also prove the toxicity of bromide residues in vegetables ... grown on treated soil" ( $p$ 144) also requires comment. Years of experience world wide with methyl bromide fumigants have shown that the inorganic bromides remaining in the soil after treatment are not toxic.

In conclusion, it must be noted that the peak values were found in conditions that deviated from the recommended practices for methyl bromide treatment of glasshouses: had the operators worked in accordance with these, they would not have been exposed to such dangerous limits. The most dangerous infringements were that they did not work from the outside, that they lacked adequate respiratory equipment and that they apparently had no means van den Ouver, Roosels, and Lahaye reply:

Methyl bromide has caused an impressive number of deaths throughout the world in all its different applications. It has been emphasised that each new application has led to a further series of poisonings because of the lack of a working knowledge of the nature of the gas and the precautions that must be taken when it is used. ${ }^{6}$

The continuous reporting of accidents with methyl bromide during soil disinfection both inside and outside Europe caused us to evaluate the hazards of soil fumigation after the banning of soil injection inside Belgian glasshouses. Gas concentrations measured using gas chromatography during and after what was generally accepted as safe fumigation were still found to be hazardous. This was despite the fact that methyl bromide could not be detected during fumigation by the smell of added chloropicrin, the method proposed by HSE in their Guidance note GS1.

At least four cases of methyl bromide poisoning have been reported in Belgium since 1979 and we are convinced that many cases among horticultural workers are missed because of deliberate concealment, neglect, and difficulties in diagnosing the often transitory signs of poisoning. We stand by our statement that the role of skin absorption in cases of poisoning may be important since this has been attested to. ${ }^{78}$

Even the best regulations and operating instructions cannot prevent accidents and infringements, just as traffic laws do not exclude accidents on the roads. There is a worldwide distinction between what is legislated for the protection of workers handling methyl bromide and the circumstances in practice.

As for the bromide regulations in vegetables grown on methyl bromide treated soil, the official residue tolerance levels differ from country to country and do not prevent the dumping on the home market of crops refused for export because of high bromide residues. There are still not sufficient data on the possible toxicity of ingested bromide. If future studies show that the manifest carcinogenic properties of methyl bromide represent a risk to 
man, the use and application of methyl bromide will have to be completely abandoned.

\section{References}

' Health and Safety Executive. Fumigation using methyl bromide (bromomethane). Guidance note GS1. London: HMSO, 1977.

${ }^{2}$ Billet and Abel. Accidents following the use of fire extinguishers charged with methyl bromide. Gazette Hopitaux (Paris) 1940;113:464.

${ }^{3}$ Butler ECS, Perry KMA, Williams JFR. Methyl bromide burns. Br J Ind Med 1945;2:30-1.
4 von Oettingen WF. The toxicity and potential dangers of methyl bromide with special reference to its use in the chemical industry, in fure extinguishers, and in fumigation. NIH Bulletin No 185.1946.

${ }^{5}$ Hegherbon WO. Handbook on toxicology. Vol III. Insecticides. Philadelphia: WB Saunders, 1959.

${ }^{6}$ van den Oever R, van de Mierop L, Lahaye D. Professionele intoxicatie door methylbromide. Arch Belg Med Soc 1978;36:353-69.

${ }^{7}$ Longley E, Jones A. Methylbromide poisoning in man. Industrial Medicine and Surgery 1965;34:499-502.

${ }^{8}$ Watrous RM. Methylbromide, local and mild systemic effect. Industrial Medicine 1942;11:575. 